\title{
NEW TYPES OF TEXTS IN HOTEL BUSINESS
}

\author{
Oksana S. Issers \\ Omsk State University named after F.M. Dostoevsky, Omsk, Russia
}

\begin{abstract}
The article reveals genre-forming characteristics and pragmatic specificity of some new text types that could characterize Russian hospitality industry with its special goal to deliver services by creating comfortable conditions for the client. Being addressed to the client of the hotel (usually call a 'guest'), the texts are presented in booklets, instructions, wall signs and located in the client residence area (hotel rooms or apartments in particular). These new text types represent certain features of "caring genre", as the hotel guides, ecologically and caring minded texts offer a kind of cognitive scenario of the guest's positive stay in the hotel by modeling the client's needs, desires, and emotional response. The author states it that this scenario makes some logical basis for the genre of guidebooks and booklets, as well as instructions and signs on walls, directed to the hotel guest's attention. The message and style of informing in the texts under study prove that there are special ways of communicating with clients, and they can be described as interactions based on institutional and interpersonal varieties of speech practice. In conclusion it is stated that the motives of hospitality industry resulted in forming a communicative-and-pragmatic discourse type for the hotel industry the features of which are presented in the article.
\end{abstract}

Key words: text, discourse, discourse practices, hotel business, hospitality language, genre, hotel guide.

Citation. Issers O.S. New Types of Texts in Hotel Business. Vestnik Volgogradskogo gosudarstvennogo universiteta. Seriya 2, Yazykoznanie [Science Journal of Volgograd State University. Linguistics], 2018, vol. 17, no. 2, pp. 53-62. (in Russian). DOI: https://doi.org/10.15688/jvolsu2.2018.2.6

\section{НОВЫЕ ТИПЫ ТЕКСТОВ В СФЕРЕ ГОСТИНИЧНОГО БИЗНЕСА}

\author{
Оксана Сергеевна Иссерс \\ Омский государственный университет им. Ф.М. Достоевского, г. Омск, Россия
}

\begin{abstract}
Аннотация. В статье рассматриваются новые в жанровом и языковом отношении типы текстов из российской сферы гостиничного бизнеса. В фокусе исследования находятся письменные тексты, адресованные клиенту (гостю) отеля и размещенные в зоне его проживания в виде буклетов, инструкций, настенных надписей, табличек и т. п. Выявлены их основные жанрообразующие характеристики и коммуникативно-прагматические особенности. Описаны такие специфические для гостиничной индустрии жанры, как путеводитель по отелю, тексты экологической направленности и «жанры заботы». Установлено, что путеводитель по отелю предлагает некий когнитивный сценарий пребывания гостя, моделируя его потребности и желания, а также эмоциональное состояние. Этот сценарий позитивного пребывания в отеле является жанрообразующим признаком текстов путеводителей и буклетов, $\infty$ адресованных гостю.

尺े Рассмотренные образцы показывают, что специфика услуг в сфере гостеприимства определяет j. особые способы общения с клиентами, формирует свойственный сфере гостиничного бизнеса дискурс-строй. Задача создать комфортные условия для проживания гостя обусловливает интердискурсиво. ность - взаимодействие институциональных и межличностных разновидностей дискурсов, что опредеЛ ляет коммуникативно-прагматическую специфику текстов буклетов и иных информационных материа() лов, размещаемых в номере отеля.
\end{abstract}


Ключевые слова: текст, дискурс, дискурсивные практики, гостиничный бизнес, язык гостеприимства, жанр, путеводитель по отелю.

Цитирование. Иссерс О. С. Новые типы текстов в сфере гостиничного бизнеса // Вестник Волгоградского государственного университета. Серия 2, Языкознание. - 2018. - T. 17, № 2. - C. 53-62. - DOI: https://doi.org/ 10.15688/jvolsu2.2018.2.6

\section{Введение. Маркетинговые стратегии как когнитивная основа формирования новых типов текстов}

Индустрия гостеприимства (как принято ее называть в туристическом бизнесе) динамично развивается как в России, так и за рубежом. Проявлением этой динамики является, в частности, высокая конкуренция, обусловленная широким спектром предложений на рынке гостиничных услуг. Маркетинговые задачи отстройки от конкурентов являются стимулом для трансформации дискурсивных практик в сфере гостиничной индустрии и возникновения новых типов текстов, адресованных клиентам. Коммуникативная цель определяет обновление приемов коммуникативного взаимодействия между представителями гостиницы (отельерами, сотрудниками) и клиентами (гостями), что находит отражение в вербальных продуктах коммуникации - текстах. Для понимания специфики таких текстов необходимо учитывать когнитивные предпосылки их порождения и восприятия.

В теории позиционирования маркетинг рассматривается как когнитивная операция, то есть это «не битва продуктов, а битва восприятий». Все, что имеется в мире маркетинга, - это восприятие клиента или потенциального потребителя. Восприятие реально, в то время как все остальное - иллюзия [Райс, Траут, 2007]. К сфере когнитивных операций относится и ключевое понятие теории позиционирования - бренд. Бренд должен формировать определенную нишу в сознании адресата. «Позиционирование - это то, как вы дифференцируете свой товар в сознании потребителей» [Траут, Ривкин, 2010, с. 106, 109]. Следовательно, моделирование в сознании адресата необходимого образа товара (услуги), отличного от других образцов категории, должно работать на его дифференциацию.

Из этого вытекает задача отстройки от конкурентов - по сути, когнитивной операции, нацеленной на создание ниши в сознании по- требителей, в которой формируется образ товара либо услуги с ее актуальными для целевой аудитории характеристиками. Для сферы гостеприимства они определяются потребностями, на удовлетворение которых направлено гостиничное обслуживание.

Актуальные для клиента потребности отражены в оценках отеля гостями - например, на специализированных сайтах типа www.booking.com. По отзывам гостей можно реконструировать типичные запросы клиентов гостиничного бизнеса. Например, «удобно для временного размещения»; «уютно, комфортно», «как дома», «по-домашнему»; «вежливый персонал»; «чисто, тихо» и т. д.

Указанные характеристики учитываются в стратегии позиционирования отеля и актуализируются в дискурсивных практиках гостиничного сервиса, таким образом формируя позитивный образ объекта в сознании потребителя.

\section{Постановка проблемы исследования}

За последние два десятилетия в отечественных и зарубежных лингвистических исследованиях сформировалась традиция классификации типов дискурса на основе преимущественного «обслуживания» тех или иных социальных сфер и институтов. Как отмечает В.И. Карасик в своем развернутом обзоре отечественных исследований дискурса, выделение типов дискурса осуществляется в рамках трех подходов: социолингвистического (кто говорит), прагмалингвистического (как говорят), тематического (о чем говорят) [Карасик, 2007, с. 348-353]. Как правило, материалом для анализа являются «прототипические образцы», не вызывающие сомнений в их идентификации с той или иной социальной сферой, а целью подобных исследований - своего рода инвентаризация дискурсов и представляющих их жанров, функционирующих в определенное время в конкретном социуме. При этом описание строится на априори принятой 
установке о наличии в данном речевом материале признаков конкретного типа дискурса. Однако в стремлении поделить весь дискурсивный континуум на типы, виды и подвиды исследователь может столкнуться с такими реалиями, которые плохо укладываются даже в самую продуманную и детализированную классификацию. Например, большинство из тех, кто не раз останавливался в отеле, замечали табличку, которую гость может повесить на дверь с просьбой «не беспокоить» либо убрать в комнате. Способов оформления этих интенций достаточно много. Две простые идеи варьируются от категорического императива Не беспокоить! до увещевательного Пожалуйста, не беспокойте (Grand Yazici, Турция), неформального Дышу свежим воздухом. Можно убрать комнату и интимного фонетического символизма, имитирующего глубокий сон, - Tсcс (Mariott Tverskaya, Москва), ...Zzz (Nevsky Hotels Group, Санкт-Петербург). Разнообразны также и способы выражения просьбы об уборке: от традиционных речевых формул Прошу убрать и Пожалуйста, убеpите в номере до невербальных символов. Вероятно, всю совокупность письменных текстов, обслуживающих дистанционные контакты гостя (клиента) и сотрудников (отельеров), нельзя назвать «гостиничным (отельным) дискурсом», но дискурсивной практикой индустрии гостеприимства - вполне возможно.

Заметим, что стандартизация текстов этой сферы преувеличена: в условиях конкурентной борьбы за клиента традиционные сообщения приобретают не свойственную им ранее экспрессию и убедительность. Так, «литературный» отель «Арина Р» (Пушкинские Горы, Псковская область) в своем буклете информирует вновь прибывших не только об оборудовании номера, но и о том эмоциональном состоянии, которое должен испытывать гость:

(1) Главный корпус отеля «Арина Р» располагает 26 двухместными номерами, а также 14 мансардными номерами. Светлые и просторные номера первого этажа, с отдельными деревянными балкончиками, подойдут даже для небольшой семьи. Мансардные номера с окнами под самой крышей создают неповторимую романтическую атмосферу - ночью потолок здесь превращается в звездное небо, а на рассвете ласковые лучики солн- ца подарят вам незабываемые минуты наслаждения жизнью. < ...> Убранство каждого номера не оставит равнодушными ценителей комфорта: чистейший воздух Пушкиногорья в сочетании с мягкостью постелей и подушек и белизной белья - все здесь располагает к расслаблению тела и души. Также в номере: мини-холодильник, доступ в Интернет Wi$\mathrm{Fi}$, телевизор, телефон, фен, комплект мягких махровых полотенец.

Активно развивающаяся индустрия гостеприимства формирует особые способы общения с клиентами. Выше мы привели примеры письменных текстов, но не меньший интерес представляют и устные формы коммуникации: общение гостей с персоналом, бронирование гостиницы по телефону и др. Можем ли мы определить тип или разновидность дискурca, который они представляют? Что это - «гостиничный (отельный) дискурс»? дискурс сферы сервиса? дискурс «коммерческого гостеприимства»? Нельзя не согласиться с мнением, что интерпретация границ дискурса как аналитическая задача рассматривает дискурс скорее как объект, созданный исследователем, а не объект без границ, существующий в действительности, «готовый» к тому, чтобы его идентифицировали и картографировали [Йоргансен, Филлипс, 2008, с. 234].

Идеи взаимодействия и конкуренции дискурсов активно обсуждаются в современной лингвистике, что нашло отражение в целой серии смежных понятий и терминов: интердискурсивность, полидискурсивность, дискурсная гетерогенность и др. В частности, В.Е. Чернявская, анализируя различные формы проявления интердискурсивности, обнаруживает в этом феномене взаимодействие различных систем знания, культурных кодов, когнитивных стратегий [Чернявская, 2016]. По мнению Е.В. Белоглазовой, «неизолированность, размытость и подвижность границ дискурсов во времени $<$.. > приводит к возникновению дискурсной гетерогенности» [Белоглазова 2010, c. 118]. Причины этого связаны с естественными условиями существования коммуникативных практик: различные дискурсы частично «накрывают» одну и ту же социальную «территорию», причем каждый дискурс конкурирует за наполнение территории своим собственным содержанием. Примером такого пересечения могут служить дискурсивные прак- 
тики сферы гостеприимства, а иллюстрацией новые типы текстов, обслуживающих данную сферу. Задача лингвиста - определить оптимальный «угол наблюдения» и попытаться максимально точно зафиксировать те феномены использования языка, которые пока не поддаются строгой классификации в рамках теории дискурса, теории текста и теории речевых жанров.

Рассмотрим с этих позиций новые типы текстов в сфере гостеприимства, складывающиеся в русскоязычной речевой практике.

\section{Материал и метод}

Институциональная сфера гостеприимства является частью туристической индустрии, внимание к которой обусловлено ее значимостью для развития национальной экономики. За последние 15 лет туристический дискурс попал в фокус исследовательского интереса: в лингвистических и междисциплинарных работах активно изучаются дискурсивные практики туристического бизнеса, в том числе и в сопоставительном аспекте, приемы аргументации, коммуникативные сценарии, нейминг (см. обзор в: [Филатова, 2012]). Однако сфера гостиничного бизнеса описана в дискурсивном аспекте менее детально [Гарифуллина, 2007; Икаева, 2014; Лиховидова, 2011; Никитина, 2006; Франтасова, 2015; Bluea, Harun, 2003] и требует более внимательного изучения, в том числе на российском материале.

В фокусе нашего внимания находятся письменные тексты, адресованные клиенту (гостю) отеля и размещенные в зоне его проживания (в номере гостиницы, апартаментах) в виде буклетов, инструкций, настенных надписей, табличек и т. п. (всего более 160 разнообразных текстов). В основном рассматриваемые тексты имеют полимодальный характер, то есть включают информацию как в текстовой, так и в визуальной формах. Значительная часть материалов представлена на двух языках - русском и английском (в том случае, если отель входит в международную гостиничную сеть, русскоязычная часть является переводом с английского). Это объясняется не только национальным составом возможных клиентов, но и тем, что в России ста- новятся все более широко представленными международные сети отелей (IBIS, Novotel и др.), в которых установлены единые стандарты бренд-коммуникации.

В целях выявления специфики указанных текстов необходимо определить их основные характеристики - коммуникативную цель, образ отправителя и адресата сообщения, структуру текста и языковую реализацию.

Речевое взаимодействие в сфере гостиничной индустрии в основном реализуется в рамках дискурсивных практик, типичных для институциональных (статусно-ориентированных) дискурсов, где представители социальных групп или институтов вступают в коммуникацию, реализуя свои статусно-ролевые позиции в рамках сложившихся общественных институтов. Стандартом институционального общения является коммуникация в своеобразных масках, что принципиально отличает институциональный дискурс от персонального (межличностного). Институциональный дискурс строится по определенному шаблону, и участники данного вида коммуникации, как правило, хорошо осведомлены об особенностях жанровой организации информации и механизмах обмена ею [Swales, 1990]. Однако степень трафаретности различных типов и жанров этого дискурса различна: существуют мягкие и жесткие разновидности институционального дискурса. По мнению В.В. Никитиной, гостиничный дискурс может быть отнесен к мягкой разновидности институционального дискурса, так как некоторые его речевые формулировки допускают вариативность [Никитина, 2006]. Именно на фоне стандартных коммуникативных практик появляются варианты, отличающие один гостиничный объект от многих других. Рассмотрим оригинальные тексты, функционирующие в сфере гостиничной индустрии, с позиций их дискурсивной специфики и жанровой идентификации.

\section{Результаты и обсуждение}

\section{Путеводитель по отелю: IBIS дума- ет о вас... \\ Ядром институционального дискурса является общение базовой пары участников коммуникации - применительно к сфере гос-}


теприимства это клиент (гость) и тот, кто оказывает услуги (сотрудник гостиницы либо отельер - владелец или управляющий отелем. Слово зафиксировано в Национальном корпусе русского языка и на портале Научно-информационный «Орфографический академический ресурс АКАДЕМОС» Института русского языка им. В.В. Виноградова РАН: http:// orfo.ruslang.ru/). Поскольку их непосредственные контакты ограничиваются несколькими типовыми ситуациями (регистрация, заселение и выезд гостя, уборка в номере), для удовлетворения возможных потребностей клиента традиционно используется буклет (книга гостя) либо памятка. В структуре большинства изданий такого рода содержатся стандартные информационные блоки: список телефонов, правила поведения, инвентарь вещей в номере, правила пожарной безопасности и др. Однако в «старых» и «новых» текстах обнаруживаются существенные различия не только в стилистике и способах оформления интенции, но и в самой интенции.

Обязательным структурным компонентом текста старого типа являются «Правила проживания в гостинице». Они представляют собой подробный список ситуаций (от поселения гостя до его выезда), строго регламентирующий поведение клиента, например в памятке из гостиницы «Планета», г. Челябинск: оформление проживания осущцествляется при предъявлении паспорта; заселение гостя производится только после оплаты проживания; проживание с домашними животными в гостинице не допускается и т. д. Большая часть «правил» носит запретительный характер и не оставляет гостю возможности выбора, о чем свидетельствует модальность долженствования: в случае задержки посетителя в номере гостя данные лица должны быть оформлены «на nодселение» (Планета, г. Челябинск). Изложение правил в основном осуществляется в жанре и стилистике юридического документа: гость / проживающий имеет право; гость / проживающий обязан, причем обязанности явно превалируют.

Речевые акты, оформленные как просьбы, по сути являются косвенным выражением регулятивных интенций - инструкции, запрета:
(2) Просьба сдавать ключи от номера каждый раз, когда вы покидаете гостиницу (Планета, г. Челябинск).

(3) Настоятельно просим вас соблюдать правила отеля и не приносить морепродукты в номера (Hyundai Hotel, г. Владивосток).

На основании рассмотренных особенностей изданий для гостя старого типа можно получить представление об образах его автора и адресата. В данном случае мы видим коллективный образ отправителя текста, максимально дистанцированный от клиента и его потребностей. В речевых актах благодарности сохраняется формальная этикетная вежливость, причем даже в этом обращении к гостю сквозит забота не о нем, а о сотрудниках отеля и содержится своего рода предписание:

(4) Благодарим за выбор нашего отеля и надеемся, что ваше пребывание будет приятным и комфортным. Со своей стороны, просим вас быть вежливыми с нашими сотрудниками и бережно относиться к оснащению номера, тем самым вы по достоинству оцените наш труд (выделение наше. О. И.) ( Планета, г. Челябинск).

Указанные выше особенности построения текста формируют представления о его адресате, нуждающемся в жесткой регламентации действий и ограниченном в выборе вариантов поведения в статусе гостя.

В отличие от обезличенных инструктивно-регламентирующих тестов старого типа отель IBIS предлагает гостю структурированный «Путеводитель по отелю», включающий следующие блоки: «Ваш сон - наша главная забота» (Слоган отеля IBIS - «Привлекательные сны по сладким ценам»), «Мы позаботимся о вас», «Оставайтесь на связи», «Доверьтесь своему вкусу». В каждом из разделов моделируется образ заботливого хозяина недаром в двух из четырех блоков наблюдается вербализация концепта 'забота'. Эта же интенция всеобъемлющей заботы, формирующая позитивный образ отельеров, эксплицируется в типичных для данного жанра речевых актах обещаний - комиссивах: мали о вас, обещуаем безоблачныци отдых, остальное мы берем на себя и т. п.:

(5) Мы подумали обо всем: современный дизайн, техническое оснащение, звукоизоляция... 
В комнатах Ibis все предназначено для Вашего удобства. Плотные занавески, которые не дадут солнечным лучам Вас побеспокоить. Пышные подушки и уютные одеяла. Как же трудно встать с кровати Ibis!

(6) Мы делаем все для Вашего комфорта и просим Вас обращаться к нам, как только что-либо нарушит Ваш покой. Остальное мы берем на себя у нас ровно 15 минут, чтобы решить любую Вашу проблему! Если мы не укладываемся в это время, все расходы - за наш счет.

Серьезный тон обязательств по обслуживанию контрастирует с неформальными ироническими сносками: Гарантия 15 минут относится к завтраку, состоянию комнаты, закускам или напиткам в баре. НО мы точно не сможем ничего поделать с погодой..

Информация о питании в отеле демонстрирует ориентацию на запросы клиента, что находит отражение в конструкциях с семантикой альтернативы (выбора):

(7) Ешьте вкусно (и досыта) днем и ночью. 24 часа в сутки. 7 дней в неделю. IBIS угощает. Горячие блюда и нежные десерты. Заказывайте их в баре или на стойке ресепшн - и уносите в свой номер, если Вам этого захочется. < .. > Приглашаем Вас попробовать наши фирменные блюда, а для тех, кто уделяет внимание здоровому питанию, мы подготовили кое-что из сбалансированного питания.

Аналогичную коммуникативную цель навигации по отелю преследует буклет «Лучшее в Novotel». Маркетинговая стратегия Novotel строится на «внимании к деталям», что декларируется на первой странице путеводителя:

(8) Почему Novotel знают и любят во всем мире? Ответ прост. Каждый гость найдет в нашем отеле сервис для себя: от конференц-зала до детского уголка, от фитнес-центра до хамама. Мы знаем, как важно внимание к деталям. Команда профессионалов Novotel всегда рада помочь Вам.

Тексты путеводителя по Novotel лишены иронии, которая есть в текстах IBIS. В то же время они, так же как и путеводители по отелю IBIS, объединены интенцией учесть возможные пожелания клиентов:

(9) В лобби первого этажа Вы можете круглосуточно воспользоваться компьютерами Макинтош с бесплатным доступом в интернет. В лобби
Вы найдете специальную игровую зону для детей от 3-х до 8-и лет.

(10) Завтрак на Ваш вкус. Выберите то, что хочется именно вам. «Ранняя пташка»- меню для тех, кто рано встает.

Назначение путеводителя не ограничивается информацией о возможностях выбора: в нем содержатся советы и рекомендации, окрашенные эмпатией по отношению к напряженному дневному графику гостей:

(11) После долгого дня деловых встреч или прогулок по городу отдохните в нашем хамаме или посетите массажный кабинет.

(12) Зарядитесь энергией в нашем фитнесцентре In Balance by Novotel. Bсе спортивное оборудование для Вас находится в свободном доступе.

Сравнение представленных выше текстов с традиционными туристическими путеводителями позволяет увидеть не только их сходство в справочно-информационной функции (см., например: [Филатова, 2012]), но и существенные различия. В отличие от туристического путеводителя, путеводитель по отелю предполагает решение ряда маркетинговых задач: формирование позитивного образа отеля как субъекта гостиничного сервиса; установление неформального контакта с клиентом; формирование спроса на дополнительные услуги; регулирование поведения гостя в рамках корпоративных требований. По сути, путеводитель по отелю предлагает некий когнитивный сценарий пребывания гостя, моделируя его потребности и желания, а также эмоциональное состояние. Именно этот сценарий позитивного пребывания в отеле и является жанрообразующим признаком текстов путеводителей и буклетов, адресованных гостю.

\section{Экологический дискурс В гостиничном интерьере}

Тема охраны окружающей среды, экономии электроэнергии и чистой воды стала привычной для западных потребителей, что находит отражение в обращениях к клиентам западных отелей и интернациональных гостиничных сетей. Эту практику подхватили и российские предприятия гостиничной индустрии, с разной степенью убедительности копирующие западные образцы. 
Базовой коммуникативной интенцией текстов экологической направленности можно считать просвещение и увещевание. Эти задачи решаются за счет разъяснения гостю значения некоторых невербальных действий:

(13) Дорогие Гости!

Полотенце, оставленное на бортике ванной или на полу, означает: «Пожалуйста, замените полотенце». Полотенце, оставленное на вешалке, означает: «Я по-прежнему им пользуюсь». Нерациональная стирка загрязняет воду. Поможем нашей природе! (гостиница «Форум», Минск).

Основанные на эмоциональной и рациональной аргументации цели экологического просвещения нередко реализуются за счет развернутой метафоры: ревья!

(14) Здесь ваши полотенца выращивают де-

Действуя в рамках программы Позитивного Гостеприимства, наш отель предлагает использовать полотенца несколько раз.

Сколько деревьев посадите сегодня Вы? Оставьте полотенца на полотенцедержателе, если хотите использовать их повторно. Средства, сэкономленные за счет сокращения потребления воды и электроэнергии, направляются на финансирование проектов по восстановлению лесных массивов. Участвуя в программе Plant for the Planet, наш отель перечисляет средства на посадку деревьев: 1 саженец в минуту по всему миру (Novotel).

Доводы к здравому смыслу являются основой убеждающей аргументации в обращении к гостям отеля Park Inn. Оформленное в виде отдельной карточки, оно озаглавлено «Имеет значение каждая капля».:

(15) Отели Park Inn by Radisson любят нашу планету. А Вы не останетесь в стороне?

Ежедневно по всему миру стираются миллионы простыней, пододеяльников и наволочек для гостиничных номеров, при этом интенсивно используются вода и стиральный порошок. Вместе с нашими гостями мы стараемся снижать объемы потребляемой нами воды. Обычно постельное белье меняется каждые три дня или при выезде в зависимости от того, что происходит раньше. В расчете на одну кровать за один день это позволяет сберегать до 15 литров воды, а также использовать меньше стирального порошка.
Если Вы все же желаете, чтобы постельное белье на вашей кровати было заменено сегодня, поместите эту карточку на подушку (Park Inn by Radisson).

В качестве аргумента для разумного расходования воды отель Radisson использует «ресурсную метафору» - сэкономленная вода есть ресурс для спасения жизни:

(16) Ваш выбор может спасти чью-то жизнь.

Последуйте примеру других гостей - используйте свое полотенце повторно. Просто повесьте его на сушку. Средств, полученных от повторного использования 250 полотенец, хватит, чтобы на всю жизнь обеспечить чистой питьевой водой одного человека. Сделайте правильный выбор! (Radisson. Resort \& Residences Zavidovo).

В качестве жанрового прототипа указанных текстов можно рассматривать социальную рекламу экологической направленности. Однако приведенные гостиничные послания отличает настойчивая и последовательная самопрезентация, не свойственная в целом социальной рекламе. В каждом из текстов имеет место экспликация собственной социальной ответственности: Отели Park Inn by Radisson любят нашу планету; наш отель перечисляет средства на посадку деревьев: 1 саженеи в минуту по всему миру. Этот признак является жанрообразующим для текстов данного типа: он отличает их от текстов других жанров экологического просвещения в иных социальных сфеpax (статьи, социальной рекламы, учебного пособия и т. п.).

\section{«Жанры заботы»}

Во всем мире в гостиничном бизнесе растет потребность в сотрудниках, умеющих налаживать эффективное общение с гостями. Цепочка коммуникаций на протяжении всего времени нахождения клиента в гостинице называется «языком гостеприимства» (этот термин можно отнести к группе терминов гостиничной индустрии [Bluea, Harun, 2003]), отсюда следует, что «язык гостеприимства» существует как в устной, так и в письменной форме. В последнем случае мы имеем возможность наблюдать разного рода послания, призванные установить более тесный контакт, пусть и дистанционно. 
К «неопознанным жанровым объектам», функционирующим в индустрии гостеприимства, можно отнести разного рода таблички, призванные установить более тесный, неформальный контакт с гостем. Стандартным в гостиничном сервисе является наличие таблички, размещаемой на двери с целью проинформировать горничную, когда она может убрать номер, не беспокоя гостя (см. об этом выше). В дискурсивных практиках интернациональных гостиничных сетей, представленных в России, наблюдается тенденция к нестандартному оформлению данной информации - за счет включения в нее личностных интонаций (они маркированы глагольными формами 1 лица и местоимением $я$ ):

(17) Сладко сплю. Просьба не беспокоить; на обороте: Я уже проснулся и вышел. Пожалуйста, заходите (IBIS). позже;

(18) Сейчас я отдыхаю. Пожалуйста, зайдите

на обороте: Пожалуйста, уберите номер (Holiday Inn).

(19) Наедине с собой. Просьба не беспокоить;

на обороте: Дышу свежим воздухом. Можно убрать комнату (Novotel).

Кроме «надверных» табличек, в гостиничных номерах размещаются и другие таблички с посланиями, свидетельствующие о заботе. Например, информация о завтраке оформлена на отдельной табличке: Уютный завтрак в Novotel. На столе гостя ожидает табличка с заботливо-дружеским:

(20) Добро пожаловать, водички? Устраивайтесь поудобнее (IBIS).

В отеле Radisson на горлышке бутылки с водой размещается неформальное сообщение Вода для тебя.

B Park Inn by Radisson горничная оставляет в убранном номере табличку:

(21) У вас чуткий сон? Если вы очень чутко спите, вы всегда можете попросить беруши у наших администраторов (Park Inn by Radisson).

Таким образом, в «языке гостеприимства» гостиничного бизнеса в России формируются новые типы текстов, ранее отсутствовавшие в дискурсивных практиках этой сферы.

\section{Выводы}

Исследование новых типов текстов в сфере гостиничного бизнеса является наглядной иллюстрацией известного в концепции социального конструкционизма тезиса о том, что дискурсивные практики всегда функционируют в диалектическом взаимодействии с другими социальными практиками. Специфика услуг в сфере гостеприимства определяет свойственный ей дискурс-строй, взаимодействие дискурсов и трансформацию жанров. Для того чтобы выиграть в конкурентной борьбе за клиента, владельцы гостиничного бизнеса вынуждены создавать такие условия для проживания гостя, которые дадут ему возможность чувствовать себя «как дома». В эти условия входит и изменение коммуникативной традиции общения с гостем, что проявляется во взаимодействии институциональных и межличностных разновидностей дискурсов. Это обнаруживается в текстах буклетов, информационных материалов, размещаемых в номере, и находит воплощение в особых «жанpax заботы», отличающих современную коммуникацию в сфере гостиничного бизнеса от общения в предшествующий период.

\section{СПИСОК ЛИТЕРАТУРЫ}

Белоглазова Е. В., 2010. Полидискурсность в контексте идей о дискурсной гетерогенности // Актуальные проблемы современной лингвистики : сб. науч. ст. СПб. : Изд-во СПбГУЭФ. Вып. 2. С. 106-121.

Гарифуллина Л. А., 2007. Сокращения в лексике индустрии гостеприимства английского и татарского языков / Л. А. Гарифуллина // Вестник ЧГУ. Гуманитарные науки. № 1. C. $149-152$.

Икаева Э. Ю., 2014. Влияние кросс-культурных факторов на содержание стандартов и практик УЧР в гостинице Novotel Moscow Centre : магист. дис. URL: http://nethash.ru/vliyaniekross-kuleturnih-faktorov-na-soderjaniestandartov-i.html (дата обращения: 10.02.18).

Йоргансен М. В., Филлипс Л., 2008. Дискурс-анализ: теория и метод. Харьков : Гуманит. центр. $350 \mathrm{c}$. 
Карасик В. И., 2007. Языковые ключи. Волгоград : Парадигма. 519 с.

Лиховидова Е. П., 2011. Вербальные средства актуализации стратегии убеждения (на материале англоязычных интернет-сайтов отелей) // Вестник Волгоградского государственного университета. Серия 2, Языкознание. № 1 (13). С. $160-165$.

Никитина В. В., 2006. Культурный сценарий и его языковое обеспечение как элемент лингвокультуры (на материале английского культурного сценария «Гостиничный сервис») : автореф. дис. ... канд. филол. наук. Самара. 22 с.

Райс Э., Траут Дж., 2007. 22 непреложных закона маркетинга. М. : АСТ. 160 с.

Траут Дж., Ривкин С., 2010. Дифференцируйся или умирай! Выживание в эпоху убийственной конкуренции. 2-е изд. СПб. : Питер. 302 с.

Филатова Н. В., 2012. Жанровое пространство туристического дискурса // Вестник Московского государственного гуманитарного университета им. М.А. Шолохова. Филологические науки. № 2. С. 76-82.

Франтасова А. М., 2015. Дискурсивные практики печатной рекламы гостиничных услуг // Известия Уральского государственного университета. Серия 1, Проблемы образования, науки и культуры. № 3 (141). С. 64-68.

Чернявская В. Е., 2016. Лингвистика текста. Лингвистика дискурса. М. : Флинта. 203 с.

Bluea G. M., Harun M., 2003. Hospitality language as a professional skill // English for Specific Purposes. № 22. P. 73-91.

Swales J. M., 1990. Genre analysis: English in academic and research settings. Cambridge : Cambridge University Press. 274 p.

\section{REFERENCES}

Beloglazova E.V., 2010. Poly-discourse phenomenon in the context of discourse heterogeneity. Aktualnye problemy sovremennoy lingvistiki: sb. nauchnykh statey. Saint Petersburg, Izd-vo SPbGUEF, iss. 2, pp. 106-121.

Garifullina L.A., 2007. Abbreviations in the lexicon of the hospitality industry in the Tatar and English languages. Vestnik Chuvashskogo gosudarstvennogo universiteta. Gumanitarnye nauki, no. 1, pp. 149-152.

Ikaeva E.Yu., 2014. The influence of cross-cultural factors on the contents of standards and human recourse management practices in Novotel Moscow Centre. Master Thesis. URL: http:// nethash.ru/vliyanie-kross-kuleturnih-faktorovna-soderjanie-standartov-i.html. (accessed 10 February 2018).

Jorgansen M.V., Phillips L., 2008. Discourse analysis as theory and method. Kharkiv, Humanities Center. 350 p.

Karasik V.I., 2007. Language keys. Volgograd, Paradigma Publ. 519 p.

Likhovidova E.P., 2011. Persuading strategy and verbal means of its realization (on the basis of the authentic English websites of hotels). Vestnik Volgogradskogo gosudarstvennogo universiteta. Seriya 2, Yazykoznanie [Science Journal of Volgograd State University. Linguistics], no. 1 (13), pp. 160-165.

Nikitina V.V., 2006. Cultural scenario and its language means as a linguacultural element (a case study of the English cultural scenario 'hotel service'). Abstract of PhD Thesis. Samara. $22 \mathrm{p}$.

Rajs E., Traut J., 2007. 22 immutable laws of marketing. Moscow, AST Publ. 160 p.

Traut J., Rivkin S., 2010. Differentiate or die: survival in our era of killer competition. Saint Petersburg, Piter Publ. 302 p.

Filatova N.V., 2012. Genre range of tourism discourse. Vestnik Moskovskogo gosudarstvennogo gumanitarnogo universiteta im. M.A. Sholohova. Filologicheskie nauki, no. 2, pp. 76-82.

Frantasova A.M., 2015. Discourse practices of print advertising of hotel services. Izvestiya Uralskogo gosudarstvennogo universiteta. Seriya 1, Problemy obrazovaniya, nauki $i$ kultury, no. 3 (141), pp. 64-68.

Chernyavskaya V.E., 2016. Text linguistics and discourse linguistics. Moscow, Flinta Publ. $203 \mathrm{p}$.

Bluea G.M., Harun, M., 2003. Hospitality language as a professional skill. English for Specific Purposes, no. 22(1), pp. 73-91.

Swales J.M., 1990. Genre analysis: English in academic and research settings. Cambridge, Cambridge University Press. 274 p. 


\section{Information about the Author}

Oksana S. Issers, Doctor of Sciences (Philology), Professor, Dean of Faculty of Philology and Media Communication, Head of Department of Theoretical and Applied Linguistics, Omsk State University named after F.M. Dostoevsky, Prosp. Mira, 55a, 644077 Omsk, Russia, isserso@mail.ru, https://orcid.org/ 0000-0003-4027-6346

\section{Информация об авторе}

Оксана Сергеевна Иссерс, доктор филологических наук, профессор, декан факультета филологии и медиакоммуникаций, заведующая кафедрой теоретической и прикладной лингвистики, Омский государственный университет им. Ф.М. Достоевского, просп. Мира, 55a, 644077 г. Омск, Россия, isserso@mail.ru, https://orcid.org/0000-0003-4027-6346 